American Journal of Applied Sciences 8 (1): 39-44, 2011

ISSN 1546-9239

(C) 2010 Science Publications

\title{
Prevalence of Depression among High School Students and its Relation to Family Structure
}

\author{
${ }^{1}$ Ali Daryanavard, ${ }^{2,3}$ Abdoulhossain Madani, ${ }^{1}$ Mohammad Saeid Mahmoodi, \\ ${ }^{1}$ Shafei Rahimi, ${ }^{1}$ Fatemeh Nourooziyan and ${ }^{1}$ Mahmood Hosseinpoor \\ ${ }^{1}$ Department of Non-Communicable Diseases, \\ Research Center for Social Determinants in Health Promotion, \\ ${ }^{2}$ Department of Public Health, School of Health, \\ ${ }^{3}$ Department of Epidemiology, Research Center for Social Determinants in Health Promotion, \\ Hormozgan University of medical sciences, Iran
}

\begin{abstract}
Problem statement: Depression is common in adolescents and especially in high school students. The aim of this study was to determine the prevalence of depression among high school students and its relation to parental configurations. Approach: A cross-sectional study was conducted during first term of the academic year 2003-2004. Data was collected by Beck Depression Inventory questionnaire (BDI-21 test) and researcher made questionnaire for demographic characteristics, using census procedure. Results: Results indicate that $31.3 \%$ of students $(23.11 \%$ of males and $39.85 \%$ of females; $p<0.0001$ ) suffer from a degree of depression (BDI score $\geq 17$ ). There was a significant relationship between depression and family structure (living with or apart of parents) $(p<0.05)$, verbal and physical quarrels of parents $(\mathrm{p}<0.001)$, physical punishment of student by his/her parents $(\mathrm{p}<0.001)$, preventing from going outside with companions $(\mathrm{p}<0.05)$, history of chronic disease in the student $(p<0.001)$, history of psychiatry disease in the family $(p<0.001)$, school dropout $(p<0.001)$ and sexual abuse $(\mathrm{p}<0.001)$. One of the most important results of this study was that $6.91 \%$ of those who have BDI score $\geq 17$ have suicidal ideation but this figure in those who have BDI score $<17$ was $1.1 \%$ $(\mathrm{p}<0.001)$. The results show that there is no significant relationship between depression and marital status, citizenry, parents literacy level, parents job, rank, smoking, alcohol ingestion and having addicted father ( $>0.05)$. Conclusion: The study findings highlight the need of psychiatry consulting and support services available to vulnerable students. Diagnosis of depression is still frequently missed and even when it is recognized, treatment is often inadequate. Then, we suggest education authorities about depression to improve recognition and diagnosis of at risk students. This recommendation should be applied to all teachers and physicians who study at schools and primary health care centers. Furthermore, further evaluation in longitudinal studies is needed to understand the stressors and risk factors leading to depression. This understanding should be used to design prevention programs at least in high school.
\end{abstract}

Kay words: Beck Depression Inventory (BDI), Epidemiologic Catchments Area (ECA), psychiatric disorders, cross-sectional study

\section{INTRODUCTION}

Man experiences a wide spectrum of mood from low to high. Mood may be high, motivated, depressed and sad. Depressive disorder is one of the commonest psychiatric disorders which is present either as offensive reactions to internal or external factors or as a certain disease as one of the common manifestations of mental disturbance in human communities.
Depression is common in adolescents and especially in high school students and is one of the most frequent mental disorders among teenagers. In this age group, fundamental impairments due to this illness, not only influence on the performance of daily tasks, but also can lead to fatal acts such as suicidal behavior. This may cause formation of unstable families in the future and finally a desperate society.

Depression often has considerable effect on quality of life, health, social and vocational performance and

Corresponding Author: Ali Daryanavard, Department of Communicable Diseases, Province Health Center, Hormozgan University of Medical Sciences, Iran 
Am. J. Applied Sci., 8 (1): 39-44, 2011

physical activities. Pincus et al. (1998) in their article, declared that between 1984 and 1994 patient visits to primary care providers for the treatment of depression are doubled. Furthermore, researches show failure to detect major depression and suboptimal use of antidepressant medications in the primary care settings and disorders remain under diagnosed and under treated (Rouchelle et al., 1996). A study related to patients who receive care at a variety of primary care centers and specialists care offices showed that only $29 \%$ of those with high severity depression have received an antidepressant (Wells et al., 1994). Another study revealed that only $45 \%$ patients who were high users of primary care services, have diagnosed with depression and in need of treatment, moreover, only 1 in 9 patients have received adequate dose and duration of antidepressant treatment (Kato and Schuberg, 1992).

In addition to complications in diagnosis and treatment of depressed patients, investigations show a difference between depression rates in different communities. According to a survey in one of the largest high schools in the United States, using Beck Depression Inventory (BDI), prevalence of mild, moderate and severe depressive disorders in the high school students was found to be 27.7, 13 and 4\%, respectively (Pincus et al., 1998). Prevalence of major depression in Epidemiologic Catchments Area study was $6.3 \%$, in Sterling County was $7.9 \%$ and in Edmonton it was $8.9 \%$ (Kaltriala-Heino et al., 1999; Lepine et al., 1997; Murphy et al., 2000; Reiger et al., 1988). In another study in Firooz-Kooh, Iran, it was found that $73 \%$ of female high school students and $58 \%$ of male high school students suffer from a degree of depression and the difference between two sexes was statistically significant. The prevalence of depression among high school students was $70.4 \%$ in Bam 10 months after earthquake (Ziaaddini et al, 2009).

This study is designed to investigate the prevalence of depression among high school students of Qeshm Island (Iran) and the distribution of the illness with respect to some of their demographic characteristics. The results of this study, not only give a prospect of severity of the problem in the island, but also, can be used as a guideline for mental health centers to choose the best method of consultations and follow them for treatment or rehabilitation.

\section{MATERIALS AND METHODS}

A cross-sectional study was conducted during first term of the academic year 2003-2004. Data was collected by Beck Depression Inventory questionnaire (BDI-21 test) and researcher made questionnaire for demographic characteristics, using census procedure. Based on the Beck Depression Inventory (BDI) which contains a 21 item self-report measure of depression severity, we measured the depression score of each student.

In this study, we dichotomized the depression score to less than 17 (no depression or mild depression) and 17 or rather (moderate, sever or extreme depression). Statistical analyses were performed using SPSS V.14.

\section{RESULTS}

A total number of 1611 students participated in the study, overall mean age of the students was $16.40 \pm 1.05$ years (mean $\pm \mathrm{SD}$ ) with the age range of $14-25$ years, of whom $51.09 \%$ (623) of them were male and $48.91 \%$ (788) were female students.

Based on the Beck Depression Inventory (BDI) which contains a 21 item self-report measure of depression severity, we measured the depression score of each student.

In this study, we dichotomized the depression score to less than 17 (no depression or mild depression) and 17 or rather (moderate, sever or extreme depression).

Results show that overall $31.30 \%$ of students suffer from a degree of depression (Score 17 or more (based on Standard Beck Test). This figure in male and female participants was 23.11 and $39.85 \%$, respectively. Depression prevalence was significantly different in female students compared with male students $(\mathrm{p}<0.0001)$.

Results show that percentage of depressed students for students with educated fathers (i.e., fathers with university level of education) was lower than those in other students.

Parents' job did not show any significant influence on their children's depression.

In this research, we consider rank of the students at birth. There is no statistical difference between those who have depression score of $\geq 17$ in respect to rank of the student at birth.

Depression rate for those students who live with both parents $(27.77 \%)$ is significantly lower than other situations and living with father alone $(40 \%)$ cause the most depression among the students $(\mathrm{p}<0.05)$.

While some risk factors such as verbal and physical quarrels of the parents, physical punishment of the student, history of chronic diseases of the student, history of psychic diseases in the family, school dropout and sexual abuse have significant influence on depression rates for both sexes, some others like smoking and alcohol consumption are significant depression factors for male students. Detailed results are presented in Table 1 . 
Am. J. Applied Sci., 8 (1): 39-44, 2011

Table 1: The relationship between depression and risk factors

\begin{tabular}{|c|c|c|c|c|c|c|c|c|c|c|c|}
\hline \multirow{3}{*}{$\begin{array}{l}\text { Beck score } \\
\text { Risk factor }\end{array}$} & \multicolumn{5}{|l|}{ Male } & \multicolumn{5}{|l|}{ Female } & \multirow[b]{3}{*}{ P-value } \\
\hline & & \multicolumn{2}{|l|}{$<17$} & \multicolumn{2}{|l|}{$\geq 17$} & \multirow[b]{2}{*}{ P-value } & \multicolumn{2}{|l|}{$<17$} & \multicolumn{2}{|l|}{$\geq 17$} & \\
\hline & & Count & Percent & Count & Percent & & Count & Percent & Count & Percent & \\
\hline Verbal quarrels & YES & 181 & 68.30 & 84 & 31.70 & \multirow[t]{2}{*}{$\mathrm{p}<0.001$} & 198 & 52.24 & 181 & 47.76 & $\mathrm{p}<0.001$ \\
\hline of parents & NO & 434 & 81.58 & 98 & 18.42 & & 261 & 68.87 & 118 & 31.13 & \multirow[b]{2}{*}{$\mathrm{p}<0.001$} \\
\hline $\begin{array}{l}\text { physical } \\
\text { quarrels }\end{array}$ & $\begin{array}{l}\text { YES } \\
\text { NO }\end{array}$ & 50 & 66.67 & 25 & 33.33 & $\mathrm{p}<0.05$ & 28 & 34.57 & 53 & 65.43 & \\
\hline of parents & & 565 & 78.15 & 158 & 21.85 & \multirow{3}{*}{$\mathrm{p}<0.001$} & 423 & 64.09 & 237 & 35.91 & \\
\hline Physical & YES & 59 & 59.00 & 41 & 41.00 & & 25 & 36.23 & 44 & 63.77 & \multirow{2}{*}{$\mathrm{p}<0.001$} \\
\hline $\begin{array}{l}\text { punishment of } \\
\text { student }\end{array}$ & NO & 562 & 79.72 & 143 & 20.28 & & 438 & 62.84 & 259 & 77.16 & \\
\hline Traveling & YES & 542 & 78.44 & 149 & 21.66 & \multirow[t]{2}{*}{$\mathrm{p}<0.05$} & 405 & 61.18 & 257 & 38.82 & \multirow[t]{2}{*}{$\mathrm{p}>0.05$} \\
\hline $\begin{array}{l}\text { outside the } \\
\text { Island }\end{array}$ & NO & 89 & 68.99 & 40 & 31.01 & & 65 & 58.08 & 53 & 41.92 & \\
\hline Traveling inside & YES & 478 & 79.53 & 123 & 20.47 & \multirow{4}{*}{$\begin{array}{l}\mathrm{p}<0.001 \\
\mathrm{p}<0.001\end{array}$} & 408 & 63.06 & 239 & 36.94 & \multirow[t]{2}{*}{$\mathrm{p}<0.05$} \\
\hline the Island & NO & 151 & 69.27 & 67 & 30.73 & & 61 & 47.29 & 68 & 52.71 & \\
\hline Preventing from & YES & 96 & 60.00 & 64 & 40.00 & & 69 & 43.13 & 91 & 66.87 & \multirow[t]{2}{*}{$\mathrm{p}<0.05$} \\
\hline $\begin{array}{l}\text { going outside } \\
\text { with }\end{array}$ & NO & 530 & 80.92 & 125 & 19.08 & & 393 & 65.07 & 211 & 34.93 & \\
\hline History of & YES & 62 & 65.26 & 33 & 34.74 & \multirow{2}{*}{$\mathrm{p}<0.05$} & 33 & 40.74 & 48 & 59.26 & \multirow[t]{2}{*}{$\mathrm{p}<0.05$} \\
\hline $\begin{array}{l}\text { chronic disease } \\
\text { in the student }\end{array}$ & NO & 523 & 79.24 & 137 & 2076 & & 403 & 63.07 & 236 & 36.93 & \\
\hline History of & YES & 36 & 57.14 & 27 & 42.86 & \multirow{2}{*}{$\mathrm{p}<0.001$} & 31 & 41.89 & 43 & 58.11 & \multirow{2}{*}{$\mathrm{p}<0.001$} \\
\hline $\begin{array}{l}\text { psychic disease } \\
\text { in the family }\end{array}$ & NO & 555 & 78.39 & 153 & 21.61 & & 421 & 62.37 & 254 & 37.63 & \\
\hline smoking & YES & 85 & 63.43 & 49 & 36.57 & \multirow{2}{*}{$\mathrm{p}<0.001$} & 26 & 49.06 & 27 & 50.94 & \multirow[t]{2}{*}{$\mathrm{p}>0.05$} \\
\hline & NO & 538 & 79.35 & 140 & 20.65 & & 443 & 61.10 & 282 & 38.90 & \\
\hline Alcohol & YES & 34 & 58.62 & 24 & 41.38 & \multirow[t]{2}{*}{$\mathrm{p}<0.05$} & 3 & 75.00 & 1 & 25.00 & \multirow[t]{2}{*}{$p>0.05$} \\
\hline Ingestion & NO & 588 & 78.09 & 165 & 21.91 & & 465 & 60.31 & 306 & 39.69 & \\
\hline Addiction & YES & 8 & 57.14 & 6 & 42.86 & $p>0.05$ & 2 & 66.67 & 1 & 33.33 & $p>0.05$ \\
\hline & NO & 615 & 77.16 & 182 & 22.84 & & 466 & 60.28 & 307 & 39.72 & \\
\hline Having addicted & YES & 20 & 64.52 & 11 & 35.48 & $\mathrm{p}>0.05$ & 13 & 48.15 & 14 & 51.85 & $\mathrm{p}>0.05$ \\
\hline Father & $\mathrm{NO}$ & 600 & 77.32 & 176 & 22.68 & & 452 & 60.92 & 290 & 39.08 & \\
\hline School dropout & YES & 121 & 70.76 & 50 & 29.24 & $\mathrm{p}<0.05$ & 43 & 40.19 & 64 & 59.81 & $\mathrm{p}<0.001$ \\
\hline & NO & 495 & 78.20 & 138 & 19.80 & & 421 & 63.69 & 240 & 36.31 & \\
\hline Sexual abuse & YES & 58 & 58.59 & 41 & 41.41 & $\mathrm{p}<0.001$ & 30 & 38.46 & 48 & 51.54 & $\mathrm{p}<0.001$ \\
\hline & $\mathrm{NO}$ & 566 & 79.16 & 149 & 20.84 & & 438 & 62.57 & 262 & 37.43 & \\
\hline
\end{tabular}

\section{DISCUSSION}

Prevalence of major depression based on Standard Beck Inventory among 2nd and 3rd level of high school students was found to be $31.30 \%$. In a depression research in a European society, $6.9 \%$ of study respondents met criteria for major depression (Kolada et al., 1994). Prevalence of major depression in Epidemiologic Catchments Area (ECA) program was $6.3 \%$, in Sterling County $7.9 \%$ and in Edmonton was 8.9\% (Kaltriala-Heino et al., 1999; Lepine et al., 1997; Murphy et al., 2000; Reiger et al., 1988).

In another study on a university population, prevalence of moderately and severely depressed students was $14 \%$ and in a study that was done in Japan the prevalence of depression in first-year university students was $20.7 \%$. In these studies Beck Depression Inventory test was used (Mkze et al., 1998; Tomoda et al., 2000).
Depression at puberty age is a great risk factor for its relapse at adulthood age, so, early diagnosis of depressed students is very important. The results of this study showed that $23.11 \%$ of boys and $39.85 \%$ of girls have depression and the female to male ratio is $1.72 / 1$. In psychiatry text books this prevalence is $5-12 \%$ for male and $10-25 \%$ for females (Sadock and Sadock, 2010).

Epidemiologic Catchments Area Study strongly suggested a gender difference in both the prevalence and incidence of major depression. In that study, prevalence ratio of female to male was $1.95 / 1$ and the incidence ratio was 2/1 (Weissman et al., 1988; Klerman et al., 1985). In another study on Philippines students who are studying in United States depression prevalence among girls was 2 times more than boys (Edman et al., 1998). Depression prevalence among girls in our study is near 2 times the boys. It indicate that some problems such as sexual abuse and some social limitation such as going outside with companions for girls are higher than for boys, that may be risk 
factors and have great role in higher prevalence of depression among girls.

Based on the results of our study, between parents job, parents' literacy and depression was not a considerable relationship, but higher literacy level of parents, especially higher education level of students' father had direct influence on lowering depression rate of the students.

Family structure and having a happy family was another factor which was considered in our study. Depression rate for those students who live with both parents was significantly lower than that for those with other living situations. Living with father caused the most depression with respect to other students. Parents' death or divorce usually damages mental health and feelings of the children. Feeling of loosing parents support could be risk factor for future depression. Kaplan point out that persons who loss one of his or her parents at the age of 13 or before have greater chance of depression (Sadock and Sadock, 2010). In a study in Bandar Abbas on high school students the relationship between depression and parents' death wasn't significant (Noorouzian and Nikooei, 1998). In our study the mean age of the depressed students at the time of his or her parent death is 9.25 years $(\mathrm{SD}=5.16$ years) which was not statistically different with that in other students.

In a study in a urban city of China, results showed that in the single-child and in non single-child groups, percentage of children who suffer from neurotic tendencies were 73 and $39 \%$ and the values for a tendency to depression were 63 and $25 \%$, respectively (Liu et al., 2003). Findings from Iranian high school students show that there isn't any relationship between rank at birth and depression (Noorouzian and Nikooei, 1998). In our study the rank hasn't significant effect on depression.

Physical punishment of students by his or her parents is an effective factor for raising the prevalence of depression and it directly affect on mental health of students. In an investigation in Finland, bulling was an important risk factor for depression (Riittakerttu et al., 1999).

Verbal and physical quarrels of parents have bad effect on mental health of students. In our study the prevalence of depression is significantly higher in this group of students.

Other risk factor that has significant effect on depression is the lack family entertainments such as traveling outside or inside the Island. Unfortunately, due to some economical or social problems, traveling inside and outside the island and family entertainment still is not a routine and common program in the island's social life of the people. Encouragement of the people for safe family entertainment leads to improvement of the people mental health.

Social limitations, especially for girls, in these traditional societies are other effective factors for depression among students. The prevalence of this risk factor in depressed girls is $54.37 \%$ and in depressed boys is $35.63 \%$. This high difference between girls and boys show that girls in this region have rather restriction than boys and it is one of the reasons of higher prevalence of depression among girls.

In several studies chronic somatic diseases have significant effect on depression (Weissman, 1987; Cantwell and Carlson, 1983). In our study, this risk factor has a significant relationship in higher prevalence of depression.

Family history of psychiatry disease is proved to be an effective risk factor for depression (Sadock and Sadock, 2010) and in our study the same results have been obtained.

The students that have addicted father have higher risk for development of depression and need special consideration and mental support.

Students with school dropout are at risk of depression then they need closed observation for depression symptoms and signs.

Smoking is one of the risk factors that its effect on depression is controversial. Some of researchers believe that there isn't relationship between depression and smoking (Lenz, 2004; Peltzer, 2003), but Hana EZ and Coworkers believe that smoking is one of hazardous behaviors that correlate with depression (Hanna et al., 2001). Regier and Coworkers findings support a strong and complicated relationship between smoking and depression. They reported that people who have ever smoked are $50 \%$ more likely to have depression and the incidence of depression in smokers is more than twice that in nonsmokers (Regier et al., 1978). In our study this relationship is statistically significant.

Kaplan believed that alcohol consumption and even history of alcohol ingestion in the family raises the risk of development of depression (Sadock and Sadock, 2010). At least 24 separated studies support the finding that $10 \%$ to $30 \%$ of alcoholics developed depression disorders (Hartka et al., 1991). The Odds Ratio (OR) for the development of depression in an alcoholic is 1.7 (Rockville,), women have higher likelihood of having 
Am. J. Applied Sci., 8 (1): 39-44, 2011

coexistent depression and alcoholic (Hartka et al., 1991). In a study on 17 to 25 years old university students, a positive association between alcohol consumption and depression symptoms was revealed (Peltzer, 2003). In a study that was performed in United States department of Health and Human Services it was shown that the prevalence of alcoholism in patient with primary depression is probably no greater than for non depressed patients (1993). In our study relationship between depression and alcohol ingestion is not significant. Of course, the rate of alcohol ingestion in this area because of religious ideation is very low and only $3.85 \%$ of students have history of alcohol consumption.

Kaplan suggests that mood disorders often occur simultaneously with substance abuse and dependence (Sadock and Sadock, 2010). In our study the relationship between depression and substance abuse isn't statistically significant. But because the prevalence of substance abuse in high school students in this study is very low $(1.73 \%$ male and $0.39 \%$ female $)$ this result isn't reliable.

One of the most important risk factors in our society is the sexual abuse. $11 \%$ of students have positive history of sexual abuse that it is very high for this area. There is not an exact study in the area about relationship between depression and sexual abuse in the literature. Prevalence of depression among these students specially the girls is high and statistically significant. Several studies have shown the relationship between depression and sexual abuse (Schraedley et al., 1999). In a study it was shown that sexual abuse between boys has greater effect on rising prevalence of depression (Schraedley et al., 1999), but in our study $41.41 \%$ of boys and $61.54 \%$ of girls that have history of sexual abuse were depressed.

\section{CONCLUSION}

The study findings highlight the need of psychiatry consulting and support services available to vulnerable students. Diagnosis of depression is still frequently missed and even when it is recognized, treatment is often inadequate. Then, we suggest education about depression to improve recognition and diagnosis of at risk students. This recommendation should be applied to all teachers and physicians who study at schools and primary health care centers. Furthermore, further evaluation in longitudinal studies is needed to understand the stressors and risk factors leading to depression. This understanding should be used to design prevention programs at least in high school. Screening depressed students by using simple techniques such BDI test or consultations in mental health centers are useful to recognize depressive symptoms in their early stages in order to refer them to psychotherapeutic intervention. Surely, it is beneficial in the short term to reduce symptoms and prevent a full depressive episode.

\section{REFERENCES}

Cantwell, D.P. and G.A. Carlson, 1983. Affective Disorders in Childhood and Adolescence: An Update. 1st Edn., SP Medical and Scientific Books, New York, ISBN: 089335189X, pp: 484.

Edman, J.L. and N.N. Andrade. J. Glipa, J. Foster and G.P. Danko et al., 1998. Depressive symptoms among Filipino American adolescents. Cultural Divers. Mental Health, 4: 45-54. DOI: 10.1037/1099-9809.4.1.45

Hanna, E.Z., H.Y. Yi, M.C. Dufour and C.C. Withmore, 2001. The relationship of early-onset regular smoking to alcohol use, depression, illicit drug use and other risky behaviors during early adolescence: Results from the youth supplement to the third national health and nutrition examination survey. J. Subst. Abuse., 13: 265-282. DOI: 10.1016/S08993289(01)00077-3

Hartka, E., B. Jonstoe and E.V. Leino M. Motoyoshi, M.T. Temple et al., 1991. A meta-analysis of depressive symptomatology and alcohol consumption over time. Br. J. Addict., 86: 12831298. DOI: 10.1111/J.1360-0443.1991.TB01704.X

Kaltriala-Heino, R., M. Rimpela, P. Rantanen and P. Laipala, 1999. Finnish modification of the 13-item Beck Depression Inventory (R-BDI) in screening an adolescent population for depressiveness and positive mood. Nord J. Psychiatry. 53: 451-457. DOI: $10.1080 / 080394899427700$

Kato, W. and H. Schuberg, 1992. Epidemiology of depression in primary care. Gen Hosp Psychiatry, 14: 237-247. DOI: 10.1016/0163-8343(92)90094-Q

Klerman, G.L., P.W. Lavori and J. Rice, T. Reich and J. Endicott, et al., 1985. Birth-cohort trends in rates of major depressive among relatives of patients with affective disorder. Arch. Gen. Psychiatry, 42: 889-893. PMID: 4015310 
Am. J. Applied Sci., 8 (1): 39-44, 2011

Kolada, J.L., R.C. Bland and S.C. Newman, 1994. Epidemiology of psychiatric disorders in edmonton. Obsessive-compulsive disorder. Acta Psychiatr Scand Suppl., 376: 24-35. PMID: 8178682

Lenz, B.K., 2004. Tobacco, depression and lifestyle choices in the pivotal early college years. JMA Coll. Health, 52: 213-220. DOI: 10.3200/JACH.52.5.213-220

Lepine, J.P., M. Gastpar, J. Mendlewicz and A. Tylee, 1997. Depression in the community: The first panEuropean study (DEPRES) (Depression Research in European Society). Int. Clin. Psychopharmacol., 12: 19-29. PMID: 9179630

Liu, C., T. Munakata, H. Fujiyama and M. Usuba, 2003. Mental health and psychological factors with single-child high school in an urban city of China. Nippon Koshu. Eisei. Zasshi. Jan., 50: 15-26. PMID: 12645142

Mkze, L.P., N.F. Nonkeleta and D.L. kize, 1998. Prevalence of depression in university population of Transkei. Curationis. 21: 32-7. PMID: 11040586

Murphy, J.M., R.R. Monson, N.M. Laird, A.M. Sobol and A.H. Leighton, 2000. A 40-year perspective on the prevalence of depression: The sterling county study. Arch. Gen. Psychiatry, 57: 209-215. DOI: 10.1001/ARCHPSYC.57.3.209

Noorouzian, F. and P. Nikooei, 1998. Evaluation of depression prevalence in high school students in Bandar, A., [Thesis], Hormozgan University of Medical Sciences, Bandar Abbas, Iran

Peltzer, K., 2003. Depressive symptoms in relation to alcohol and tobacco use in South African university students. Psychol. Rep., 92: 1097-1098. DOI: 10.2466/PR0.92.4.1097-1098

Pincus, H.A., T.L. Tanielian, S.C. Marcus, M. Olfson and D.A. Zarin et al., 1998. Prescribing trends in psychotropic medication: primary care, psychiatry and other medical specialties. JAMA, 279: 526-531. DOI: $10.1001 /$ jama.279.7.526

Regier, A.D., I.D. Goldberg and A.C. Taube, 1978. The de facto U.S. mental health services system: A public health perspective. Arch. Gen. Psychiatry, 35: 685-693.

Reiger, D.A., J.H. Boyd, J.D.J.R. Burke, D.S. Rae and J.K. Myers et al., 1988. One-month prevalence of mental disorders in the united states. Based on five epidemiologic catchments area sites. Arch. Gen. Psychiatry, 45: 977-986.
Riittakerttu, K.H., M. Marttunen, A. Rimpela and P. Rantanen, 1999. Bullying, depression and suicidal ideation in Finnish adolescents: School survey. BMJ, 319: 348-351.

Rouchelle, A.M., R. Pound and J.G. Tierney, 1996. Depression. In: Textbook of Consultation-Liaison Psychiatry, Rundell, J.R. and M.G. Wise (Eds.). American Psychiatric Press, Washington DC, pp: 310-345.

Sadock, B.J. and V.A. Sadock, 2010. Kaplan and Sadock's Pocket Handbook of Clinical Psychiatry. 5th Edn., Lippincott Williams and Wilkins, New York, ISBN: 1605472646, pp: 576.

Schraedley, P.K., I.H. Gotlib and C. Hayward. 1999. Gender differences in correlates of depressive symptoms in adolescents. J. Adolesc. Health, 25: 98-108. DOI: 10.1016/S1054-139x(99)00038-5

Tomoda, A., K. Mori, M. Kimura, T. Takahashi and T. Kitamura, 2000. One-year prevalence and incidence of depression among first-year university students in Japan: a preliminary study. Psychiatry Clin. Neurosis, 54: 583-588. DOI: 10.1046/J.14401819.2000.00757.X

Weissman, M.M., 1987. Advances in psychiatric epidemiology: Rates and risks for major depression. Am. J. Public Health, 77: 445-451. DOI: 10.2105/AJPH.77.4.445

Weissman, M.M., P.J. Leaf and G.L. Tischler D.G. Blazer and M. Karno 1988. Affective disorders in five United States communities. Psychol. Med., 18: 141-153. DOI: $10.1017 /$ S0033291700001975

Wells, K.B., W. Katon, B. Rogers and P. Camp, 1994. Use of minor tranquilizers and antidepressant medications by depressed outpatients: Results from the medical outcomes study. Am. J. Psychiatry, 151: 694-700. PMID: 7909411

Ziaaddini, H., N. Nakhaee and K. Behzadi, 2009. Prevalence and correlates of PTSD among high School Students After the arthquake disaster in the city of Bam, Iran. Am. J. Applied Sci., 6: 130-132. DOI: 10.3844/ajassp.2009.1 